Nigel L.P. Symons MBbs FFaracs, Hal K. Leaver MBBS

\title{
Air embolism during craniotomy in the seated position: a comparison of methods for detection
}

A case of air embolism sufficient to cause cardiovascular collapse is reported. This occurred during biopsy of the trigeminal nerve with the patient in the seated position. The use of an end-tidal carbon-dioxide monitor was a better indicator than a precordial doppler of the embolic problem. It allowed rapid detection and prompt resuscitation to be carried out. Air embolism is a significant and potentially fatal problem in clinical practice. It has been widely reported during neurosurgical, head and neck, and gynaecological prcoedures, and increasingly during laparoscopic procedures where carbon dioxide or air may be embolized systemically.

A discussion of the incidence and pathophysiology as well as a review of the methods of diagnosis and management follows.

\section{Key words}

ANAESTHESIA; neurosurgical; EMBOLISM: systemic, air; MONITORING: end-tidal carbon dioxide.

From the Department of Anaesthetics, Royal North Shore Hospital of Sydney, St. Leonards, NSW, Australia.

Address correspondence to: Dr. N.L.P. Symons, Department of Anaesthesia, The Montreal General Hospital, 1650 Cedar Avenue, Montreal, PQ, Canada H3G 1 A4.
Systemic air embolism is a serious and potentially fatal complication of many surgical procedures. ${ }^{1-6}$ The reported incidence varies widely, depending upon the accuracy of diagnosis, since many small emboli pass either unnoticed or undiagnosed, 1,7 Prompt treatment obviously requires both early and accurate diagnosis. A number of methods have been suggested to monitor for such problems notably the praecordial ultrasonic doppler and end-tidal carbondioxide analysis. The following case report describes the effectiveness of both of these methods in diagnosing an embolic problem, and the use of the endtidal capnograph in quantitating both the severity of the physiological insult and the effectiveness of treatment.

\section{Case history}

A 74-year-old female presented for investigation and treatment of progressive left-sided cranial nerve palsies, and increasing left-sided facial pain. She had developed a left Bell's palsy in 1976, and during the six months prior to admission had increasing deafness, dysarthria and diplopia. She was grossly wasted, weighing $40 \mathrm{~kg}$. Palsies of the fifth to the tenth cranial nerves on the left side were present. Preoperative blood pressure was $170 / 90$ torr; she had no evidence of ischaemic or valvular heart disease. Electrocardiogram and chest $x$-ray were normal. Brain scan, angiography and CT scan were normal, and therefore biopsy of the fifth cranial nerve via the Frazier approach (i.e. lateral, subtemporal approach to the Gausserian ganglion) was planned to obtain a tissue diagnosis.

The patient was premedicated with atropine $400 \mu \mathrm{g}$ intramuscularly one hour before induction. 


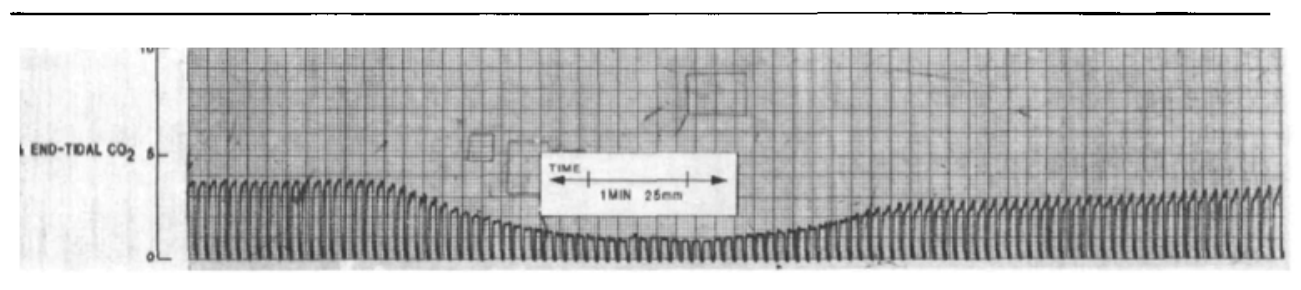

FIGURE Continuous end-tidal carbon dioxide tracing showing venous air embolism. Carbon dioxide measured with a Datex CD-300 end-tidal capnograph.

On arrival in the pre-anacsthetic room a right radial arterial line, left antecubital central venous line and right peripheral venous line were inserted. Chest $x$-ray confimed the tip of the central line to be in the mid-right atrium.

Prior to induction both legs were bandaged with elasticized bandages up to the groins. Infusion of four per cent dextrose and 0.18 per cent saline was commenced and anaesthesia was induced with fentanyl $100 \mu \mathrm{g}$, thiopentone $75 \mathrm{mg}$ and pancuronium $4 \mathrm{mg}$. The trachea was intubated and anaesthesia maintained with 30 per cent oxygen, nitrous oxide and 0.25 per cent enflurane. The pulse rate remained steady at $80 / \mathrm{min}$ and systolic arterial pressure (SAP) ranged between 110-130 torr during placement of the patient in the sitting position.

After placement in the sitting position, end-tidal carbon dioxide measurements were commenced using a Datex CD-300 end-tidal carbon dioxide analyser (calibrated to ten per cent $\mathrm{CO}_{2}$ in 70 per cent $\mathrm{N}_{2} \mathrm{O}$ ). The end-tidal $\mathrm{CO}_{2}$ was maintained between three and four per cent. An ultrasonic doppler (Parks Electronic Laboratory Model 915-L dual frequency doppler with cautery suppressor and 2-20 transducer) was placed over the fourth right intercostal space slightly lateral to the manubrium. This was coupled with aquasonic coupling medium and firmly strapped into place. Continuous arterial pressure and electrocardiograph monitoring had been used from the time of induction.

About $30 \mathrm{~min}$ after adopting the seated position (approximately $10 \mathrm{~min}$ after commencement of surgery), as the dura was exposed, the end-tidal $\mathrm{CO}_{2}$ fell (Figure). The fall in end-tidal carbon dioxide preceded other changes by $30-45 \mathrm{sec}$. The systolic arterial pressure fell from 130 to 30 torr and the pulse rate rose from 80 to 180 beats per min. At the same time the ST segments fell $3 \mathrm{~mm}$. The changes in doppler sound occurred at the time the arterial pressure fell. Heart sounds became muffled. A diagnosis of air embolism was made.

Since the patient was held in a head frame and the table had been "broken" to the sitting position, adoption of the head down position was not possible. Therefore the patient was placed in 30 degree headup tilt and the legs were raised approximately 60 degrees. The wound was flooded with saline.

The patient was ventilated on 100 per cent oxygen and enflurane discontinued. The CVP line was aspirated and $30-40 \mathrm{ml}$ of air and "frothy" blood obtained. The patient remained hypotensive and $1 \mathrm{mg}$ metaraminol was given intravenously. The systolic pressure rose after this to 160 torr, and coincided with an increase in end-tidal $\mathrm{CO}_{2}$ levels; however, the latter took about $15 \mathrm{~min}$ to return to previous levels (for the same minute ventilation). With the return of arterial pressure, ST segments became isoelectric and heart rate slowed to $120 \mathrm{~min}$. Nitrous oxide and enflurane were then cautiously re-introduced. A small diploic vessel was thought to be the site of entrainment and this was plugged with bone wax.

The operation was completed uneventfully with the patient at approximately 45 degree head up tilt. The patient was ventilated for three hours postoperatively in the intensive care unit and then extubated. Electrocardiogram and chest $x$-ray performed one hour postoperatively were unchanged. Neurological examination following extubation was similarly unchanged.

\section{Discussion}

Venous air embolism is a well recognized hazard in patients undergoing neurosurgical procedures, especially in the seated position. ${ }^{1-3}$ It has been reported in head and neck surgery, ${ }^{2}$ following 
laparoscopy ${ }^{4}$ and gynaecological procedures in the Trendelenberg position. ${ }^{5}$ Multiple episodes of air embolism in a child undergoing posterior fossa craniotomy has recently been reported. ${ }^{6}$

The overall incidence is not known but has been reported as varying from $1.6-93$ per cent, with a mortality between 0 and 73 per cent. ${ }^{1,7}$ This obviously reflects the methods and accuracy of detection of the embolus, and the clinical effects that these may have, since many obviously pass undiagnosed. '

The effects of venous air embolism are related to the size of the embolus and the rate at which air (or other gas) is entrained. The $\mathrm{LD}_{50}$ for humans has been reported as $300 \mathrm{ml}$ but very large volumes have apparently been tolerated when given slowly. Animal experiments (mainly in dogs), have shown a fall in end-tidal $\mathrm{CO}_{2}$ after $0.18 \mathrm{ml} \cdot \mathrm{kg}^{-1}$ with obvious falls in end-tidal $\mathrm{CO}_{2}$ and cardiac output following $1.5 \mathrm{ml} \cdot \mathrm{kg}^{-1} .^{7}$ It was further shown by Oppenheimer that the left lateral position was associated with a better clinical outcome than either right lateral or supine positions. ${ }^{8}$

The monitoring of patients to detect air embolism can be divided into (i) general, non-specific monitoring such as pulse rate, electrocardiograph, ${ }^{9}$ arterial pressure $^{10}$ and respiratory pattem (if patient breathing spontaneously); and (ii) more specific methods such as end-tidal carbon dioxide analysis ${ }^{1,11}$ and the doppler ultrasonic flow transducer. ${ }^{1.12}$ Changes in heart sounds themselves are supposed to be detectable by a suitably placed oesophageal stethoscope ${ }^{1,13}$ More recently, detection of nitrogen in the anaesthetic circuit by mass spectrometry has been shown to be a very sensitive indicator or pulmonary air embolism. Any sudden increase in end-tidal nitrogen as measured by mass spectrometry is indicative of air embolism, and the volume of air can be accurately quantitated.*

In our patient the first sign of embolism was the fall in the end-tidal carbon dioxide to one per cent. This preceded the fall in arterial pressure and the change in doppler sound by about $45 \mathrm{sec}$. This is contrary to what has been reported by others where the doppler ultrasound is said to be the most sensitive monitor, allowing detection of very small

*Severinghaus, J.W. Air embolism detected by mass spectrometry. Anaesthesiology News 1982; 8: 9. amounts of air. 1,14,16 This may reflect non-ideal placement of the doppler probe, since the Tinker test was not used. ${ }^{17}$ Thurlow, ${ }^{18}$ however, reported the capnograph to be more reliable in clinical practice.

The treatment of air embolism must be aimed at correcting the physiological disturbance caused, and preventing further embolisation. It has been suggested that the wound be flooded with saline ${ }^{3}$ and the patient placed in the left lateral and head-down position (Durant Manouvre) ${ }^{8}$ Nitrous oxide should be discontinued as this will reduce the size of the embolus. ${ }^{19}$ Conversely, the use of $\mathrm{N}_{2} \mathrm{O}$ may increase the size of an embolus.

If a central line is in position then attempts should be made to aspirate air from the right atrium. ${ }^{1,3} \mathrm{lt}$ has been suggested that a Swan-Ganz catheter be inserted in patients undergoing surgery in positions which are prone to embolic phenomena. ${ }^{20.21}$

The pathophysiology of this condition is such that air can lie in the right atrium, right ventricle or pulmonary arteries _-all of which lead to an "airlock" situation with right ventricular outflow obstruction. ${ }^{5}$ The CVP or (JVP) is seen to rise ${ }^{1}$ as does the pulmonary artery pressure due to air liberating humoral agents, and causing both reflex and humoral vasoconstriction. ${ }^{5,20}$ Thus air emboli produce their effect by obstruction of the pulmonary artery, and impairment of gas exchange. Consequently, hypotension and hypoxia occur. Clinical manifestations may include increasing rate and depth of respiration (in a spontaneously breathing subject), diffuse pulmonary wheeze, cyanosis, hypotension and arrhythmias, and a mill wheel murmur. ${ }^{1.2,5}$

Treatment must be aimed at restoration of arterial pressure and control of arrhythmias, if they occur. The use of isoproterenol has been advocated to overcome the reflex pulmonary vasoconstriction and also increase myocardial contractility, and so improve the right ventricular outflow. Alternatively a peripheral vasoconstrictor ${ }^{2}$ such as metarminol or methoxamine has been used to raise arterial pressure, improve coronary perfusion and to increase the venous return to the right side of the heart.

Prevention of venous air embolism begins by recognising which patients are at risk. In the case presented, the end-tidal $\mathrm{CO}_{2}$ monitor provided the first indication that air embolism had occurred, and immediate treatment was able to be effected. A change in doppler sounds occurring after the fall in 
end-tidal $\mathrm{CO}_{2}$. While it could be argued that a change in doppler sounds is qualitative, the endtidal $\mathrm{CO}_{2}$ monitor provides a quantitative measurement of the physiological insult, and gives a clear indication of the success or otherwise of treatment. The end-tidal capnograph is therefore a sensitive and non-invasive indicator of air embolism. We recommend that it be included in the monitoring of patients at risk of air embolism.

\section{References}

1 Buckland $R W$, Manners $J M$. Venous air embolism during neurosurgery-a comparison of various methods of detection in man. Anaesthesia 1976; 31 : 633-43.

2 Huner AR. Air embolism in the sitting position. Anacsthesia 1962; 17: 467-72.

3 Edelman $J D$, Wingard $D W$. Air embolism arising from burr holes. Anesthesiology 1980; 53: 167-8.

$4 \mathrm{McQuaide} J R$. Air embolism arising during peritoneoscopy. S Afr Med J 1972; 46: 422-3.

5 Nauly JS, Meisel LB, Datta S, et al. Air embolism during radical hysterectomy. Anesthesiology 1982; 57: 420-2.

6 Porter SS, Boyd RC, Albin MS. Venous air embolism in a child undergoing posterior fossa craniotomy: a case report. Can Anaesth Soc J 1982; 31 : 86-90.

7 Hunter D, Sevel PS. Detection of venous air cmbolism. Anaesthesia 1979; 34: 578-82.

8 Oppenheimer $M J$, Durant $T M$, Lynch $P$. Body position in relation to venous air embolism and the associated cardiovascular respiratory changes. Am J Med Sci 1953; 225: 362-73.

9 Whitby $I D$. Electrocardiography during posterior fossa operations. Br J Anaesth 1963; 35: 624-30.

10 Durant TM, Long J, Oppenheimer MJ. Pulmonary (venous) air embolism. Am Heart J 1947; 33: 269-81.

11 Bethune RWM, Brechner VL. Detection of venous air embolism by carbon dioxide monitoring. Anesthesiology 1968; 29: 178.

12 Edmonds-Seal J, Mardon JC. Air embolism diagnosed with ultrasound. A new monitoring technique. Anaesthesia 1969; 24: 438-40.

13 Marshall $B M$. Air embolus in neurosurgical anaesthesia: its diagnosis and treatment. Can Anaesth Soc J 1965; 12: 255-61.

14 Gildenberg $P L, O^{\prime} B$ rien $R P$, Britt $W J$, etal. Efficacy of doppler monitoring for detection of venous air embolism. J Neurosurg 1981; 54: 75-8.
15 Edmonds-Seal J, Prys-Roberts $C$, Adams AP. Air embolism. A comparison of various methods of detection. Anaesthesia 1971; 26: 202-8.

16 "A Practice of Anaesthesia." Edited by H.C. Churchill-Davidson. Lloyd-Duke (Medical Books) Lid. London, 1979, p. 981, 2nd Ed.

17 Tinker JH, Gronerf GA, Messick JM Jr, et al. Detection of air embolism: a test for positioning of right atrial catheter and doppler probe. Anesthesiology 1975; 43: 104-6.

18 Thurlow $A C$. Use of capnography in the differential diagnosis of acute cardiovascular changes during posterior fossa exploration in the sitting position. Br J Anaesth 1981; 53: 313.

19 Munson ES, Merrick HC. Effect of nitrous oxide on venous air embolism. Anesthesiology 1966; 27: 783-7.

20 Perkins-Pearson NAK, Marshall WK, Bedford RF. Atrial pressure in the seated position. Implications for paradoxical air embolism. Anesthesiology 1982; 57: 493-7.

21 Khan MA, Alkalay I, Suetsugu S, et al. Acute changes in lung mechanics following pulmonary emboli of various gases in dogs. J Appl Physiol 1972; 83: 774-7.

\section{Résumé}

Un cas d'embolie gazeuse en quantité suffisante pour provoquer un collapsus cardiovasculaire est rapporfe. Ceci est survenu lors d'une biopsie du nerf trijtsmeau en position assise. L' utilisation d' un moniteur de $\mathrm{CO}_{2}$ en fin d'expiration offrait un meilleur indice que le doppler précordial pour le problème embolique. Il a permis une détection rapide ainsi que l'établissement sans délai des manoeuvres de réanimation. L'embolie gazeuse est un problème significatif et potentiellement fatal en clinique. Il a été largement rapporté lors de la neurochirurgie, chirurgie du crâne et du cou, procédure gynécologique et d'une façon croissante lors des procédures laporascopiques, que le $\mathrm{CO}_{2}$ oul'air peuvent emboliser lacirculation systémique.

Une discussion de l'incidence et de la physiopathologie ainsi qu'une revue des différentes méthodes diagnostiques et des conduites à tenir sont présentées. 